\title{
Third-Year Progress Report on DOE-EMSP Grant DOE-DE-FG07-99ER15022: "Immobilization of Radionuclides in the Hanford Vadose Zone by Incorporation in Solid Phases"
}

\author{
Gordon E. Brown, Jr. (P.I.), Jeffrey G. Catalano, Jeffrey A. Warner*, Samuel Shaw**, and \\ Daniel Grolimund*** \\ Department of Geological \& Environmental Sciences \\ Stanford University, Stanford, CA 94305-2115
}

\begin{abstract}
* present address: Division of Chemical Sciences, Lawrence Berkeley National Laboratory
** present address: Department of Earth Sciences, Oxford University, Oxford, U.K.

*** present address: Swiss Light Source, Paul Scherrer Institute, Laussane, Switzerland
\end{abstract}

\section{Background}

The Department of Energy's Hanford Nuclear Site located in Washington State has accumulated over 2 million curies of radioactive waste from activities related to the production of plutonium (Ahearne, 1997). Sixty-seven of the single-shelled tanks located at the site are thought to have leaked, allowing between 2 and 4 million liters of waste fluids into the underlying vadose zone. The chemical processes employed at the Hanford Site to extract plutonium, as well as the need to minimize corrosion of the high-carbon steel storage tanks, resulted in uncharacterized hyperalkaline waste streams rich in radionuclides $\left({ }^{137} \mathrm{Cs},{ }^{90} \mathrm{Sr},{ }^{60} \mathrm{Co}\right.$, ${ }^{99} \mathrm{Tc},{ }^{234},{ }^{238} \mathrm{U}$, and others) as well as other species including significant amounts of sodium and aluminum (Boomer et al., 1994).

Aluminum originated in the tank waste primarily as a result of the REDOX chemical processing technique used from 1952 to 1966 (Katz and Seaborg, 1972). A limited data set from the Tank Waste Information Network (http://twins.pnl.gov:8001/) indicates that most Hanford Tanks (with the possible exception of the B, C, and T tank series) contain on the order of 40,000 ppm of aluminum, which corresponds to total aluminum concentrations of about $1.5 \mathrm{M}$. Associated with these high concentrations of aluminum are high $\mathrm{pH}$ values $(\mathrm{pH}=9-14)$, high ionic strengths (greater than $5 \mathrm{M}$ due to $\mathrm{NO}_{3}^{-}, \mathrm{NO}_{2}^{-}, \mathrm{Cl}^{-}, \mathrm{SO}_{4}{ }^{2-}, \mathrm{CO}_{3}{ }^{2-}, \mathrm{Na}^{+}, \mathrm{UO}_{2}{ }^{2+}$, and others), and in some cases high temperatures (Serne and Wood, 1990; Flanagan, 1994). Under these conditions the likely speciation of the aluminum is the aluminate ion and as a solid precipitate.

There is concern about the fate and transport of radionuclides in these leachates and their interactions with components of the vadose zone. Dissolution and precipitation reactions driven by the high $\mathrm{pH}$ of the leachates or other reactions resulting from their complex chemistry likely raise unique geochemical problems. Due to the high aluminum concentrations, one possibility is that aluminum gels immediately precipitate in the tanks and that these gels act to sequester radionuclides contained in the waste, such as ${ }^{90} \mathrm{Sr}$. Another scenario might be the coprecipitation of hydrous Al-hydroxides with other contaminants as leachates flow away from the tanks and their $\mathrm{pH}$ is buffered by the soil matrix.

As part of a larger collaborative project involving Samuel Traina (Ohio State University), Calvin Ainsworth and John Zachara (Pacific Northwest National Laboratory), and the Brown 
Research Group at Stanford University, we have investigated adsorption processes that could lead to the sequestration of $\mathrm{Cr}, \mathrm{Co}, \mathrm{Sr}$, and $\mathrm{U}$ on minerals representative of the Hanford Vadose Zone sediments and precipitation processes resulting in alkali aluminate solids that form from the highly alkaline and aluminum-rich leachates reacting with these sediments. These elements are among the most important pollutants of concern to the Department of Energy at the Hanford Site in Washington State. The aqueous solutions used in these experiments were simplified surrogates of Tank leachates (i.e., they contained high $\mathrm{Na}$ and $\mathrm{Al}$ and had $\mathrm{pH}$ values of 10-12 in many cases). We have examined the following processes that could lead to sequestration of these pollutant elements: (1) the sorption/coprecipitation of these elements in solids formed from reaction of alkaline aluminate solutions with simple systems of minerals representative of those found in the soils and sediments underlying the Hanford Tank Farm (e.g., quartz, feldspars, clay minerals, iron oxides); (2) the sorption/coprecipitation of these elements in solids formed from reaction of alkaline aluminate solutions with soil and sediment samples obtained from the Hanford site; and (3) the effect of aging on the stability of sorption complexes on Al-oxide and Al-oxyhydroxide surfaces formed from neutralization and homogeneous nucleation of alkaline aluminate solutions. Our investigations have utilized X-ray Absorption Fine Structure (XAFS) spectroscopy, electron and X-ray microprobe analyses, X-ray diffraction and small angle X-ray scattering, and inductively coupled plasma emission spectrometry analysis, as described below.

\section{Accomplishments}

A brief summary of our findings to date on eight research projects is included, and the status of each project is given. The primary participants in each study are indicated.

(1) Speciation of Cr in Hanford Vadose Zone Borehole Samples from Beneath the S-SX Tank Farm (John C. Zachara, Jeffrey G. Catalano, Jeffrey A. Warner, Samuel J. Traina, and Gordon E. Brown, Jr.) (the results of this study were presented at the $222^{\text {nd }}$ National Meeting of the American Chemical Society, Chicago, IL: Catalano et al. (2001a); this study is now in press: Zachara et al., Geochim. Cosmochim. Acta 2003, 67) - Highly radioactive subsurface core samples from a high level nuclear waste vadose zone plume at the Hanford site containing elevated concentrations of $\mathrm{Cr}$ and other contaminants were studied to provide insights on the future mobility of $\mathrm{Cr}$. $\mathrm{Cr}(\mathrm{VI})$ is one of several risk-driving contaminants at the Hanford Site. The plume originated from the leakage of self-boiling REDOX process tank waste supernatant in 1969 that contained high concentrations of alkali $(\mathrm{NaOH} \approx 5.25 \mathrm{~mol} / \mathrm{L})$, salt $\left(\mathrm{NaNO}_{3} / \mathrm{NaNO}_{2}>10\right.$ $\mathrm{mol} / \mathrm{L})$, aluminate $\left[\mathrm{Al}(\mathrm{OH})_{4}{ }^{-}=3.36 \mathrm{~mol} / \mathrm{L}\right], \mathrm{Cr}(\mathrm{VI})(0.413 \mathrm{~mol} / \mathrm{L})$, and ${ }^{137} \mathrm{Cs}^{+}\left(6.51 \times 10^{-5} \mathrm{~mol} / \mathrm{L}\right)$. Water and acid extraction of the oxidized subsurface sediments indicated that a significant portion of the total $\mathrm{Cr}$ was associated with the solid phase. Mineralogic analyses, $\mathrm{Cr}$ valence speciation measurements by X-ray adsorption spectroscopy (XAS), and small column leaching studies were performed to identify the chemical retardation mechanism and leachability of Cr. While X-ray diffraction detected little mineralogic change to the sediments from waste reaction, scanning electron microscopy (SEM) showed that mineral particles proximate to the point of tank failure were coated with secondary, sodium aluminosilicate precipitates. The density of these precipitates decreased with distance from the source. The XAS and column studies demonstrated the reduction of $29-75 \%$ of the total $\mathrm{Cr}$ to insoluble $\mathrm{Cr}(\mathrm{III})$, and the apparent precipitation of up to $28 \%$ of the $\mathrm{Cr}(\mathrm{VI})$ as an unidentified, non-leachable phase. Both $\mathrm{Cr}(\mathrm{VI})$ reduction and $\mathrm{Cr}(\mathrm{VI})$ precipitation were greater in sediments more proximate to the leak source 
where significant mineral alteration was noted by SEM. These and other observations implied that basic mineral hydrolysis driven by large concentrations of $\mathrm{OH}^{-}$in the waste stream liberated $\mathrm{Fe}$ (II) from the otherwise oxidizing sediments that served as a reductant for $\mathrm{CrO}_{4}{ }^{2-}$. The coarsetextured Hanford sediments contain silt-sized mineral phases (biotite, chlinochlore, magnetite, and ilmenite) that are sources of $\mathrm{Fe}(\mathrm{II})$ at high $\mathrm{pH}$. Other dissolution products $\left(\right.$ e.g., $\left.\mathrm{Ba}^{2+}\right)$ or $\mathrm{Al}(\mathrm{OH})_{4}^{-}$present in the waste stream may have induced $\mathrm{Cr}(\mathrm{VI})$ precipitation as $\mathrm{pH}$ moderated through mineral reaction. The results demonstrated that a minimum of $42 \%$ of the total $\mathrm{Cr}$ inventory in all of the samples was immobilized as $\mathrm{Cr}(\mathrm{III})$ and $\mathrm{Cr}(\mathrm{IV})$ precipitates that are unlikely to dissolve and migrate to groundwater under the low drainage conditions of the Hanford vadose zone.

(2) Co Speciation in Precipitates Formed from Alkaline Aluminate Solutions (Jeffrey G. Catalano, Jeffrey A. Warner, and Gordon E. Brown, Jr.) (The results of this study were presented at the $222^{\text {nd }}$ National Meeting of the American Chemical Society, Chicago, IL: Catalano et al. (2001b); a manuscript is in preparation which combines section (2) with section (3) below and will be submitted to Applied Geochemistry) - To investigate the phase controlling Co(II) solubility in alkaline aluminate solutions, both at room temperature and an elevated temperature representative of the waste tanks, EXAFS spectroscopy was used to characterize the phase(s) formed in this model system. The samples analyzed consisted of Co(II) co-precipitated into an Al-hydroxide gel, formed by mixing $1 \mathrm{mM} \mathrm{Co}\left(\mathrm{NO}_{3}\right)_{2}$ with $0.3 \mathrm{M} \mathrm{Al}\left(\mathrm{NO}_{3}\right)_{3}$ in a background of $2 \mathrm{M} \mathrm{NaNO}_{3}$. This was followed by the addition of $10 \mathrm{~N} \mathrm{NaOH}$ until the $[\mathrm{OH}] /[\mathrm{Al}]$ ratio $=4$. Samples were sealed and aged at $25^{\circ} \mathrm{C}$ or $80^{\circ} \mathrm{C}$ for 6 days. The solid phase from each sample was collected as a wet paste and sealed in a Teflon sample holder for EXAFS analysis.

EXAFS spectra of $\mathrm{Co}(\mathrm{II})$ in the solid phase are nearly identical for the $25^{\circ} \mathrm{C}$ and $80^{\circ} \mathrm{C}$ samples. The fitting results are consistent with the Co-Al hydrotalcite-like precipitate characterized by Thompson et al. (1999a,b). As this is a Si-free system, silicate clay formation is not possible. However, the structural parameters derived from the EXAFS are also consistent with $\alpha-\mathrm{Co}(\mathrm{OH})_{2}$, which recently has been shown to posses a hydrotalcite-like structure. As the second shell may also be fit with a slightly more disordered shell of all $\mathrm{Co}$, distinguishing a mixed Co-Al hydrotalcite phase from $\alpha-\mathrm{Co}(\mathrm{OH})_{2}$ is not possible through EXAFS alone. Therefore, it appears that the solubility of $\mathrm{Co}$ (II) in alkaline aluminate solutions may be controlled by either a mixed Co-Al hydrotalcite phase or $\alpha-\mathrm{Co}(\mathrm{OH})_{2}$.

\section{(3) Co Sorption onto Hanford Vadose Zone Sediments (Jeffrey G. Catalano, Jeffrey A.}

Warner, and Gordon E. Brown, Jr.) (The results of this study were presented at the $222^{\text {nd }}$ National Meeting of the American Chemical Society, Chicago, IL: Catalano et al. (2001b); a manuscript that combines these results with those discussed in section (2) above is in preparation for submission to Applied Geochemistry.) - To investigate the potential interactions of waste leachates with the sediments they are leaking into, $\mathrm{Co}(\mathrm{II})$ and $\mathrm{U}(\mathrm{VI})$-bearing solutions were reacted with uncontaminated sediment samples from Hanford. Two sediment samples from the Hanford Formation, the uppermost stratigraphic unit at the Hanford site, were obtained for these studies. They are from two separate locations - the ERDF and the Submarine pits. These samples will be referred to as ERDF and Sub sediments, respectively. The ERDF sediment 
sample is fine-grained sand, while the Sub sample is fine sandy silt. Both consist of predominantly quartz, plagioclase, and K-feldspar.

Although the identity of the Co(II) phase in Sub sediments cannot be ascertained from the EXAFS data alone, a few conclusions may be drawn based on our results. While the solubility of $\beta-\mathrm{Co}(\mathrm{OH})_{2}$ was exceeded in these experiments, the EXAFS-derived $\mathrm{Co}^{\mathrm{II}}-\mathrm{O}$ and $\mathrm{Co}^{\mathrm{II}}-\mathrm{Co}$ distances are too short to be $\beta-\mathrm{Co}(\mathrm{OH})_{2}$. However, the Co-Co distances are consistent with $\mathrm{Co}(\mathrm{II})$ in a hydrotalcite-like structure (e.g., the $\mathrm{Co}-\mathrm{Al} \mathrm{HT}$ or $\alpha-\mathrm{Co}(\mathrm{OH})_{2}$ ) or a silicate clay (e.g., Co analog of kerolite).

The Co K-XANES data indicate a mixture of Co(II) and Co(III) in the Sub sediment samples, but mostly $\mathrm{Co}(\mathrm{III})$ in the ERDF sediment samples The difference in oxidation state of Co between the two sediments may be due to differences in sediment mineralogy. The high $\mathrm{pH}$ of the solutions caused significant dissolution of phases in the Sub and ERDF samples, indicated by relatively high dissolved Si (Sub: $0.6 \mathrm{mM}$; ERDF: $0.4 \mathrm{mM}$ ) and Al (Sub: $71 \mathrm{mM}$; ERDF: 55 $\mathrm{mM}$ ). The Sub sediments contain significantly more Fe(II)-bearing phases, including biotite, chlorite, and amphibole. Dissolution of these Fe(II)-bearing phases liberates significant amounts of $\mathrm{Fe}^{2+}{ }_{\text {(aq) }}$ to solution. Thus, the Sub sediments in high $\mathrm{pH}$ solutions provide more available $\mathrm{Fe}$ (II) for reaction due to the presence of these Fe(II)-bearing minerals. The mineralogy of the Sub sediments appears to inhibit Co oxidation.

(4) U(VI) Sorption onto Montmorillonite and onto Model Sediment Phases in the Hanford Vadose Zone (Jeffrey G. Catalano and Gordon E. Brown, Jr.) (The results of this study were presented at the $222^{\text {nd }}$ National Meeting of the American Chemical Society, Chicago, IL: Catalano et al. (2001b); a manuscript is in preparation for submission to Geochim. Cosmochim. Acta.) - Montmorillonite is a ubiquitous clay mineral in many sediments, including those in the Hanford vadose zone. However, sequestration of actinides like U(VI) depend on a number of variables, including soil $\mathrm{CO} 2$ levels and varying groundwater ionic strengths. We have used EXAFS spectroscopy to investigate the effects of these two variables on the structure of U(VI) adsorption complexes on montmorillonite. Uranium(VI) was reacted with Wyoming montmorillonite SWy-2 (( $\left.\left.\mathrm{Ca}_{.12} \mathrm{Na}_{.32} \mathrm{~K}_{.05}\right)\left[\mathrm{Al}_{3.01} \mathrm{Fe}(\mathrm{III})_{.41} \mathrm{Mn}_{.01} \mathrm{Mg}_{.54} \mathrm{Ti}_{.02}\right]\left[\mathrm{Si}_{7.98} \mathrm{~A}_{1.02}\right] \mathrm{O}_{20}(\mathrm{OH})_{4}\right)$ obtained from the Source Clay Repository. SWy-2 was pretreated to remove excess carbonates by soaking in a pH 5.0 sodium acetate buffer. $5 \mu \mathrm{M} \mathrm{UO} \mathrm{UO}_{2}\left(\mathrm{NO}_{3}\right)_{2}$ was reacted with $250 \mathrm{mg}$ of SWy-2 in $\mathrm{CO}_{2}$-equilibrated solutions containing 1 and $5 \mathrm{M} \mathrm{NaNO}_{3}$, and in $1 \mathrm{M} \mathrm{NaNO}_{3}$ with 10 $\mu \mathrm{M} \mathrm{Na}_{2} \mathrm{HPO}_{4}$. These samples were allowed to react for 24 hours at $\mathrm{pH} \mathrm{7,} \mathrm{at} \mathrm{which} \mathrm{time} \mathrm{they}$ were centrifuged, and the solids were collected as a wet paste for XAFS analyses.

Least-squares fits of $\mathrm{U} \mathrm{L}_{\mathrm{III}}$-edge EXAFS spectra of the samples suggest possible inner-sphere surface complexes or surface precipitates. Si or Al backscatterers at about $3.0 \AA$ and $3.55 \AA$ are consistent with binding to silanol and aluminol sites, respectively. Distant $\mathrm{U}$ backscatterers indicate possible precipitates or multi-nuclear surface complexes. Finally, $\mathrm{C}$ and $\mathrm{P}$ backscatterers suggest possible ternary surface complexes; distances are consistent with previously reported carbonate and phosphate ligand distances. The nature of U(VI) adsorption complexes is slightly influenced by ionic strength, and significantly influenced by the presence of dissolved $\mathrm{PO}_{4}{ }^{3-}$. 
To investigate the possible sequestration mechanisms of uranium in Hanford vadose zone sediments, $50 \mu \mathrm{M}$ and $1 \mathrm{mM} \mathrm{UO}\left(\mathrm{NO}_{3}\right)_{2}$ were reacted with $250 \mathrm{mg}$ of the Sub sediments at $\mathrm{pH}$ 12.8 in a $1 \mathrm{M} \mathrm{NaNO}_{3}$ background electrolyte open to the atmosphere. Additionally, $50 \mu \mathrm{M}$ $\mathrm{UO}_{2}\left(\mathrm{NO}_{3}\right)_{2}$ was reacted with the Sub sediments in the presence of $0.1 \mathrm{M} \mathrm{Na}_{2} \mathrm{HPO}_{4}$, and $1 \mathrm{mM}$ $\mathrm{UO}_{2}\left(\mathrm{NO}_{3}\right)_{2}$ in the presence of $0.1 \mathrm{M} \mathrm{NaHCO}_{3}$. The samples were reacted for 24-hours, after which they were centrifuged, and the solid phases were collected for XAFS analyses. EXAFS data demonstrate a strong solution dependence on the structure of $U$ in the sorption products, and thus a strong dependence on the form of $U$ removal. Fits to the data show significant changes in the first oxygen shell. In the carbonate- and phosphate-free samples, the first oxygen shell has a single peak in the Fourier transform of the EXAFS data, consistent with a uranate-type structure. However, the first oxygen peak splits in the presence of phosphate and carbonate, consistent with a uranyl-type structure. These spectra suggest that in the presence of Hanford sediments, U may partition to the solid phase as uranyl- or Na-uranate-like precipitates, depending on solution conditions.

\section{(5) Aging of Co-precipitated Strontium in Al-Oxyhydroxide Gels (Jeffrey A. Warner, Jeffrey}

G. Catalano, and Gordon E. Brown, Jr.) (The results of this study were presented at the $222^{\text {nd }}$ National Meeting of the American Chemical Society, Chicago, IL: Warner and Brown (2001); a manuscript is in the final stages of preparation and will be submitted to Geochim. Cosmochim. Acta.) - The uptake of strontium during the crystallization of aluminum hydroxides may represent a potentially important process affecting the mobility and sequestration of strontium at the Hanford site. At the concentrations present in many contaminated sites precipitation, coprecipitation or the formation of a solid solution is likely a more significant sequestration mechanism than adsorption. However, little is known about the formation and evolution of these mixed systems in terms of their stability and potential for remobilization. An important factor in the determination of the stability of these systems is the identity of the precipitated solid phase. Coprecipitation of impurities in gel systems may inhibit dissolution/reorganization processes thereby stabilizing metastable systems (Combes et al., 1989, 1990). In a mixed kaolinite and simulated Hanford tank waste leachate system, Chorover et al. (2003) found that a strontium phase (postulated to be a strontium aluminum silicate) formed rapidly and had the effect of decreasing the kaolinite dissolution rate.

In the case of aluminum, the solid phase that first forms is dependant on many factors including, the degree of supersaturation $(\mathrm{OH} / \mathrm{Al}$ ratio, $\mathrm{pH}$ and total concentration of aluminum), ionic strength, identity of counter-ions and even the order and rates of addition of various reagents (Hsu, 1967, van Straten et al., 1984a,b,c). This sensitivity to solution conditions is typical of primary particle formation and stability in precipitation reactions, which are often controlled by solvation and structural interactions rather than by van der Waals and electrostatic interactions. In a system supersaturated with respect to many possible precipitates often the thermodynamically least stable solid is the first to form ("Ostwald Rule of Stages"). This is relevant in the current study because at at room temperature there are potentially four solid modifications of of aluminum hydroxides that can form. As argued by Reeder et al. (2001), the formation of a discrete strontium phase (e.g. $\left.\mathrm{SrCO}_{3}\right)$ may result in solubility being controlled by that phase versus the bulk dissolution required to release strontium from a dilute solid solution. In addition, there is ample reason to suspect that the inclusion of ions may stabilize some aluminum solids with respect to others. The three polymorphs of aluminum trihydroxide are 
gibbsite, bayerite and nordstrandite with bayerite being the most thermodynamically stable and gibbsite being more naturally abundant (Hsu, 1989). The three polymorphs differ primarily in their stacking order, which may be affected by both the extent of inclusion of an impurity and its identity. The morphology of gibbsite has been found to differ as a function of the presence of potassium versus sodium (Lee et al., 1996).

Previous studies have documented the significant sorption and co-precipitation of strontium with aluminum hydroxide solid phases in controlled systems (Kinniburgh et al., 1976; Kinniburgh et al., 1975; Frere and Champion, 1967). Field data from a new borehole at Hanford (SX-108 slant borehole) show relatively low activities of ${ }^{90} \mathrm{Sr}$ (compared to ${ }^{137} \mathrm{Cs}$, despite an estimated fission yield of 1:1 suggesting that strontium may be still in or just beneath the tank (Serne, 2000). At other sites (e.g. tank B-110), there is the suggestion that ${ }^{90} \mathrm{Sr}$ may be quite mobile but ${ }^{90} \mathrm{Sr}$, with no readily identifiable gamma ray, poses a problem in terms of plume location, generally, ${ }^{90} \mathrm{Sr}$ plumes are inferred from high energy Bremsstrahlung radiation.

In this investigation, we begin by showing the changes in aluminum solid phase as a function of various initial chemical parameters, using Al K-edge x-ray absorption near edge spectroscopy (XANES) and x-ray diffraction (XRD). Strontium co-precipitation with aluminum gel solid phases is compared to strontium adsorption/precipitation on aluminum powders and these systems are analyzed using strontium K-edge x-ray absorption fine-structure (EXAFS) spectroscopy, in order to characterize the local molecular environment of the strontium. An important component of this study is the aging of the Al systems and the comparison of aged systems to "fresh" samples using the techniques described above. It is expected that in these systems strontium carbonate will be an important species because of the high $\mathrm{pH}$ values.

\section{Aluminum Gels}

Aluminum gels were made by adding $10 \mathrm{~N} \mathrm{NaOH}$ at an injection rate of $1 \mathrm{~mL} / \mathrm{min}$. to solutions of aluminum nitrate $(0.1$ and $0.5 \mathrm{M})$ and sodium nitrate $(10 \mathrm{mM}$ and $2 \mathrm{M})$. Hydroxideto-aluminum mole ratios of 2.8, 3.0, 3.2 and 4.0 (corresponding to $\mathrm{pH}$ values of approximately 4, 6,11 , and 13) were used in strontium sorption experiments, XANES and x-ray diffraction measurements at various aluminum and background sodium nitrate solution concentrations. After aging the gels in suspensions at room temperature, $50^{\circ}$ and $80^{\circ} \mathrm{C}$ they were subsequently investigated using the same techniques as those applied to the non-aged samples.

\section{Characterization of Aluminum Gels}

Fresh and aged gels were analyzed by x-ray diffraction, Al K-edge XANES and Sr Kedge EXAFS. The gels were rinsed with distilled water prior to analysis and allowed to air-dry. Al K-edge XANES (1559.6 eV) were collected on beamline 3-3 at the Stanford Synchrotron Radiation Laboratory (SSRL) using a channeltron to detect the total electron yield and calibrated against Al foil.

\section{Strontium Uptake on Aluminum Gels and Powders}

Strontium sorption experiments on $\mathrm{Al}$ gels and $\mathrm{Al}$ hydroxide powders (boehmite, bayerite and gibbsite) at a range of background concentrations of sodium nitrate and $\mathrm{pH}$ values were conducted. Strontium uptake and the extent of aluminum dissolution were monitored using a TJA ICP-AE spectrometer with a measured detection limit of $10^{-8} M$ strontium and $10^{-5} M$ 
aluminum. These detection limits are matrix dependant but were measured at the concentration of sodium nitrate used in this investigation. BET sample surface area was measured on the Al powders using a Coulter SA3100 surface area and pore size analyzer. Surface areas measured for a CONDEA boehmite and bayerite were 270 and $9.9 \mathrm{~m}^{2} / \mathrm{g}$, respectively. Gibbsite, received from Biakowski Malokoff Inc., had a BET surface area of $0.40 \mathrm{~m}^{2} / \mathrm{g}$.

\section{EXAFS Model Compounds}

Strontium feldspar $\left(\mathrm{SrAl}_{2} \mathrm{Si}_{2} \mathrm{O}_{8}\right)$ was synthesized following the procedure of McGuinn and Redfern (1994). Briefly, strontium carbonate $\left(\mathrm{SrCO}_{3}\right)$, silica $\left(\mathrm{SiO}_{2}\right)$ and corundum $\left(\mathrm{Al}_{2} \mathrm{O}_{3}\right)$ were dried overnight. After cooling, the compounds were mixed in a $\mathrm{Pt}$ crucible in the appropriate stoichiometric ratio, ground and heated in stages from $500^{\circ} \mathrm{C}$ to $1300^{\circ} \mathrm{C}$ and subsequently to $1500^{\circ} \mathrm{C}$. The sample was re-ground after 30 hours, and spent a total of $74 \mathrm{hrs}$ at $1500^{\circ} \mathrm{C}$. Mass loss from decarbonation was consistent with the formation of $\mathrm{SrAl}_{2} \mathrm{Si}_{2} \mathrm{O}_{8}$. An xray diffraction pattern matched that of strontium feldspar. Strontium carbonate was obtained from Aldrich and used without further purification.

\section{EXAFS Experiments}

Sorption samples were analyzed as wet pastes using EXAFS spectroscopy. Sr K-edge EXAFS were collected on beamline 4-3 at the Stanford Synchrotron Radiation Laboratory (SSRL) with Si (220) monochromator crystals and using a solid-state 13 element Ge fluorescence detector. The beam was detuned about $50 \%$ at $16300 \mathrm{eV}$ for all scans. Beam energy was calibrated by assigning the first inflection point on the absorption edge of yttrium foil to $17038 \mathrm{eV}$. Multiple scans (19-40) were collected on all samples, the exact number depending on the signal-to-noise ratio achieved for any particular sample. Sample preparation for EXAFS experiments followed the same procedure used for the sorption experiments.

\section{EXAFS Fitting}

EXAFS analysis was performed using the RXSAP suite of programs (Hayes and Boyce, 1982). Spectra were averaged and the pre-edge region subtracted. Spectral post-edges for reference compounds and experimental samples were filtered over similar $\mathrm{k}$ ranges and Fouriertransformed. Fits were performed in $\mathrm{r}$-space to isolate individual shell contributions. Values of the amplitude reduction factor, $\mathrm{S}_{0}{ }^{2}$, and the energy origin, $\mathrm{E}_{0}$ were obtained from FEFF 7 generated phase and amplitude functions fits of EXAFS measured model compounds; strontium feldspar $\left(\mathrm{SrAl}_{2} \mathrm{Si}_{2} \mathrm{O}_{8}\right)$ and strontium carbonate $\left(\mathrm{SrCO}_{3}\right)$. Fits were made using ATOMs (Ravel, 2001) generated FEFF input files from the crystal structure of Benna and Bruno (2001). Fits of the strontium feldspar were made between 1.2 and $5 \AA$ and were of high quality $(\mathrm{R}<10 \%)$. Values of the amplitude reduction factor and $\mathrm{E}_{0}$ were applied to the experimental fits of the sorption spectra. In order to identify difficulties caused by the correlation between $\mathrm{S}_{0}{ }^{2}$, the coordination number $(\mathrm{N})$ and $\sigma$ in the experimental data, a comparison of the Debye-Waller factor was made with $\mathrm{S}_{0}{ }^{2}$ constrained and unconstrained. In a previous study, it was shown that a third cumulant $\left(\mathrm{C}_{3}\right)$ term was unnecessary in fit functions because first-shell anharmonic disorder was generally not significant (O’Day et al., 2000).

In order to model the conditions in the Hanford tanks and leachates as closely as reasonably possible, most experiments in this study used background electrolyte concentrations in excess of $2 \mathrm{M}$ sodium nitrate. These high ionic strengths as well as the limited understanding of aluminum speciation at high concentrations presents some difficulty in terms of knowing the 
aqueous speciation of aluminum in some of these batch systems.

\section{Results}

Figure 1 shows a comparison of the x-ray diffraction patterns of the aluminum precipitate that forms as a function of aluminum concentration, $\mathrm{OH} / \mathrm{Al}$ ratio and aging time. Patterns were obtained within one day for fresh gels, after rinsing (to remove the $2 \mathrm{M}$ sodium nitrate solution) and air-drying. The plot shows that at the highest $\mathrm{Al}$ concentration, $\mathrm{OH} / \mathrm{Al}$ ratio and aging temperature and time, gibbsite is formed. Based on XRD, gibbsite is not formed under other milder conditions. At the lowest aluminum concentration $(0.3 \mathrm{M})$ and an $\mathrm{OH} / \mathrm{Al}$ mole ratio of 3 , the formation of pseudoboehmite is indicated, upon increasing the $\mathrm{OH} / \mathrm{Al}$ mole ratio, bayerite forms. Aging at $80^{\circ} \mathrm{C}$ for 25 days has the effect of having pseudoboehmite form despite the fact that without aging the formation of bayerite is indicated (Figure 1).

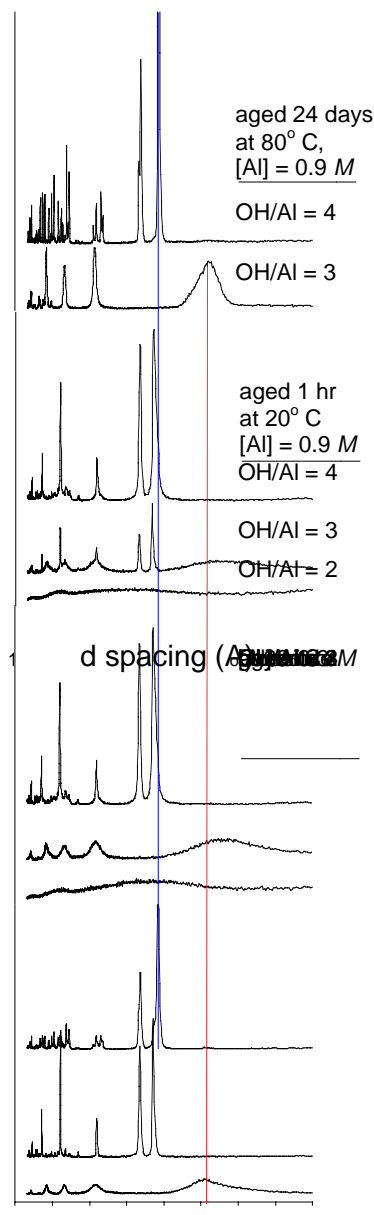

Figure 1. XRD of freshly precipitated and aged $\mathrm{Al}$ gels with a comparison to model compounds. The plot shows the variation in $\mathrm{Al}$ phase as a function of $\mathrm{OH} / \mathrm{Al}$ mole ratio, $\mathrm{Al}$ concentration and aging. The dotted line indicates a peak characteristic of gibbsite. Diffraction patterns (a-f) represent; (a) $[\mathrm{Al}]=0.3 \mathrm{M}$ and $\mathrm{OH} / \mathrm{Al}$ ratio $=$ 3 , (b) $[\mathrm{Al}]=0.3 \mathrm{M}$ and $\mathrm{OH} / \mathrm{Al}$ ratio $=4$, (c) $[\mathrm{Al}]=0.9 \mathrm{M}$ and $\mathrm{OH} / \mathrm{Al}$ ratio $=3,(\mathrm{~d})[\mathrm{Al}]=0.9 \mathrm{M}$ and $\mathrm{OH} / \mathrm{Al}$ ratio $=4$, (e) $[\mathrm{Al}]=0.9 \mathrm{M}$, $\mathrm{OH} / \mathrm{Al}$ ratio $=3$, aged 25 days @ $80^{\circ} \mathrm{C}$, and (f) $[\mathrm{Al}]=0.9 \mathrm{M}, \mathrm{OH} / \mathrm{Al}$ ratio $=4$, aged 25 days @ $80^{\circ} \mathrm{C}$.

As a further check on the identity of the aluminum precipitate that forms in these systems, samples were analyzed using Al K-edge XANES. Samples were prepared for XANES by filtering precipitation solutions and allowing these to air-dry before being applied as a thin powder to conducting grids. Total electron yield of the samples was measured at $\sim 10^{-7}$ torr. Samples showed some differences in the measured spectra as a function of the initial aluminum 
concentration, $\mathrm{OH} / \mathrm{Al}$ mole ratio and aging time and temperature. Increasing the initial aluminum concentration at constant $\mathrm{OH} / \mathrm{Al}$ mole ratio produced a boehmite-like precipitate at $0.1 \mathrm{M} \mathrm{Al}$ and a bayerite-like solid at $0.3 \mathrm{M} \mathrm{Al}$ (Figs. 2a and 2b). Figures 2c-e show the differences recorded between freshly precipitated samples and samples aged for seven days at $50^{\circ}$ and $80^{\circ} \mathrm{C}$. At $80^{\circ}$ $\mathrm{C}$, gibbsite is identified as the precipitate.

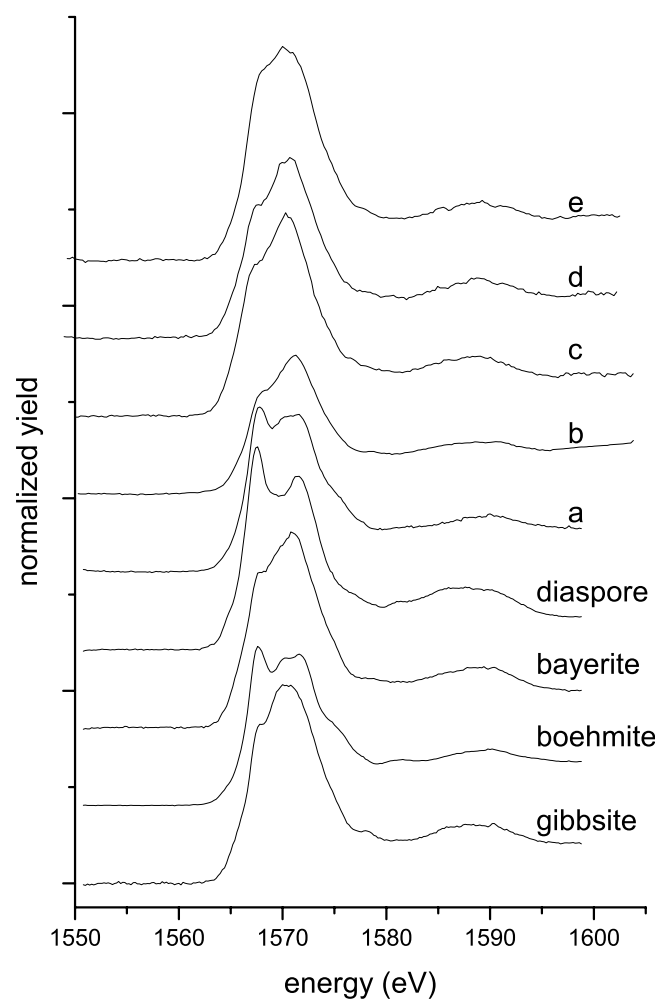

Figure 2. Normalized Al K-edge XANES of aluminum model compounds, gibbsite, boehmite, bayerite and diaspore as well as experimental aluminum hydroxide precipitate samples. Plots (a-e) represent, (a) $[\mathrm{Al}]=0.1 \mathrm{M}$ and $\mathrm{OH} / \mathrm{Al}$ $=3$, (b) $[\mathrm{Al}]=0.3 \mathrm{M}$ and $\mathrm{OH} / \mathrm{Al}=3$, (c) $[\mathrm{Al}]=0.3 \mathrm{M}$ and $\mathrm{OH} / \mathrm{Al}=4$, (d) $[\mathrm{Al}]=0.3 \mathrm{M}, \mathrm{OH} / \mathrm{Al}=4$ and aged at $50^{\circ}$ $\mathrm{C}$ for 7 days, and (e) $[\mathrm{Al}]=0.3 \mathrm{M}, \mathrm{OH} / \mathrm{Al}=4$ and aged at $80^{\circ} \mathrm{C}$ for 7 days.

Figure 3 shows the equilibrium strontium adsorption onto $\mathrm{Al}$ powders as a function of $\mathrm{pH}$. There is a slight (\%) increase in strontium adsorption as the $\mathrm{pH}$ is increased from 9 to 12 for gibbsite, bayerite and boehmite. The largest increase is seen with gibbsite.

At a given ionic strength at $\mathrm{pH} \mathrm{10,} \mathrm{the} \mathrm{strontium} \mathrm{adsorption} \mathrm{of} \mathrm{the} \mathrm{aluminum} \mathrm{solid}$ powders differs by about an order of magnitude. The initial adsorption for all three powders is greater than $98 \%$, but gibbsite adsorption is affected the most by an increase in ionic strength. Gibbsite has significantly higher strontium adsorption than the other powders. The percent adsorption of strontium by gibbsite drops to $0.32 \%$. Bayerite is able to retain the most strontium, in terms of surface coverage, whereas boehmite retains the most on a percentage basis being relatively unaffected by the increases in sodium nitrate concentration. Above $0.3 \mathrm{M}$ sodium nitrate the adsorption of strontium begins to decrease and becomes a function of the electrolyte concentration. 


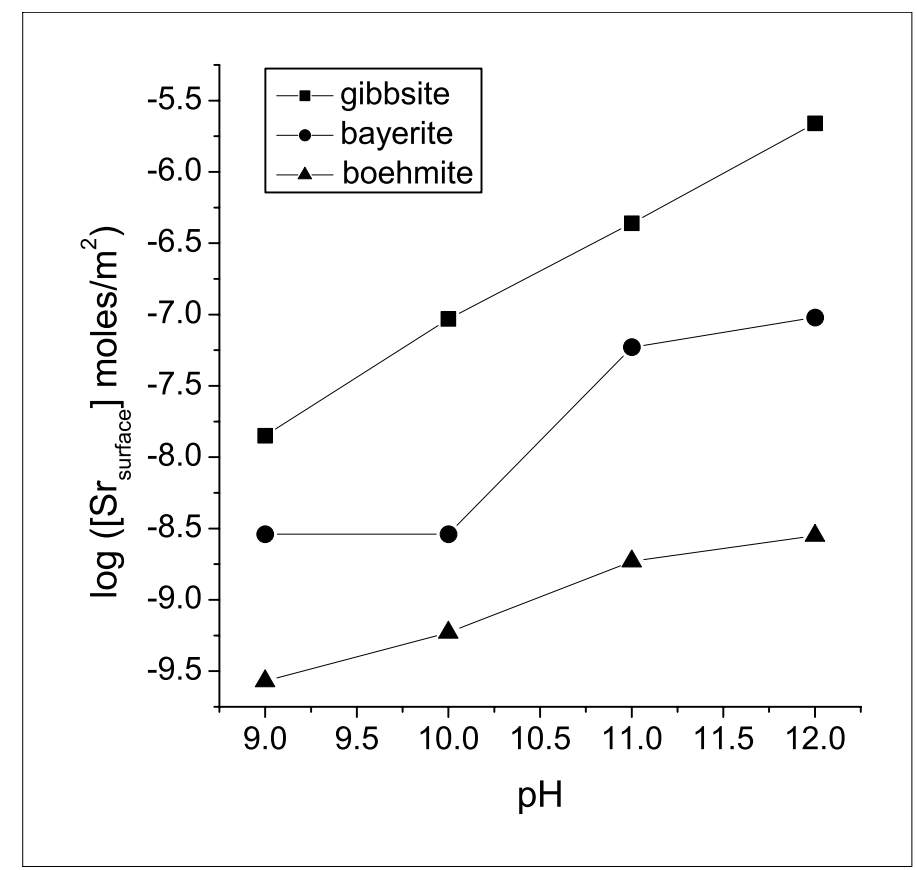

Figure 3. Changes in Sr uptake on Al hydroxide powders (gibbsite, bayerite and boehmite) as a function of $\mathrm{pH}$.

Figure 4 shows the k-space spectra of aged samples at two different background electrolyte concentrations. The k-space spectra were Fourier transformed over a k range of 2.5 to $9.2 \AA^{-1}$. The amplitude of the k-space spectra is decreased as the aging time of the samples increase. The reduction in amplitude seems to be constant as a function of $\mathrm{k}$ suggesting a change in amplitude rather than an increase in the harmonic disorder factor, $\sigma^{2}$.
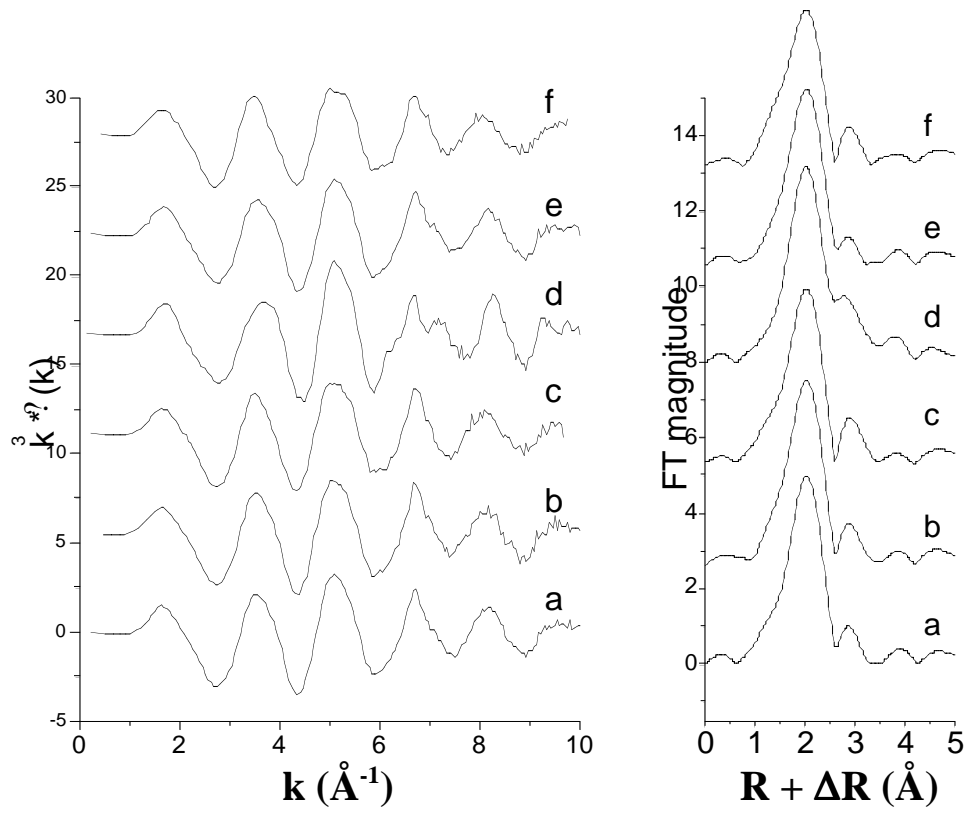

Figure 4. Experimental Sr K-edge EXAFS (left) and their Fourier transforms (right) of aged mixed strontium-Al gel systems. For all spectra $[\mathrm{Sr}]=0.001 \mathrm{M}, \mathrm{OH} / \mathrm{Al}=3.25$ and the background electrolyte is $2 \mathrm{M} \mathrm{NaNO}_{3}$. (a) $[\mathrm{Al}]=0.1$ $\mathrm{M}$ aged for 15 days at room temp, (b) 15 days @ $50^{\circ} \mathrm{C}$, and (c) 5 days @ $80^{\circ} \mathrm{C}$ (c); and with $[\mathrm{Al}]=0.9 \mathrm{M}$, aged for 15 days @ room temp (d), 15 days @ 50 $\mathrm{C}(\mathrm{e})$, and 5 days @ 80 $\mathrm{C}(\mathrm{f})$. 
(6) Chemical Behavior of Strontium at the Solid-Liquid Interface of Amorphous Manganese Oxides: A Molecular-level Study using EXAFS (Daniel Grolimund, Xavier Carrier, Jeffrey A. Warner, and Gordon E. Brown, Jr.) (The results of this study were presented at the 2000 Goldschmidt Conference in Oxford, U.K. (Grolimund et al., 2000); a manuscript is in the final stages of preparation for submission to Geochim. Cosmochim. Acta.) - Strontium-90 (half-life = 28 years), a product of uranium fission, is released to the environment from the normal operation of nuclear reactors, nuclear plant accidents, nuclear weapons testing, waste streams associated with fuel processing and leakage from radioactive waste storage facilities. It is one of the major radioactive contaminants in the Hanford vadose zone. Based on total inventory, half-life, and biological activity, ${ }^{90} \mathrm{Sr}$ is one of the most important radionuclides released from nuclear reactors in the first one hundred years of disposal. As a result, the selective retention of strontium by specific components of soil and water is extremely important because these retardation mechanisms (e.g., adsorption, precipitation, etc.) may prevent the migration of the radionuclide for times that assures its decay to insignificance.

Several cases of ${ }^{90} \mathrm{Sr}$ contamination of groundwater and surface water resources have been reported in the literature [refs]. As a prominent example, concentrations of ${ }^{90} \mathrm{Sr}$ exceed the drinking water standard by almost 10 -fold in ground water in some areas around Hanford in Washington state. In addition, plumes containing ${ }^{90} \mathrm{Sr}$ intersect the Columbia River. Interactions of aqueous strontium ions with natural solid phases have been recognized as playing a key role in controlling the transport, fate, and bioavailability of ${ }^{90} \mathrm{Sr}$.

Manganese (hydr)oxides are particularly important solid phases in the environment, where they occur as fine-grained aggregates, fresh-water nodules or concretions, crusts and coatings on mineral particles and rock surfaces. Numerous laboratory and field studies have revealed an exceptional reactivity of natural manganese phases [Bertsch]. Given their reactivity and ubiquity in the environment, it is important to understand their impact on Sr mobility.

Macroscopic uptake and molecular-level spectroscopic investigations were conducted to elucidate the chemical behavior of aqueous $\mathrm{Sr}$ at the $\delta$-Mn oxide solid-solution interface. Sorption isotherm measurements revealed a pronounced reactivity of the Mn oxide - Sr system documented by fast reaction kinetics and a high affinity of $\mathrm{Sr}$ for the Mn oxide surface. The observed uptake behavior is characterized by a pronounced non-linearity of sorption isotherms indicative of chemical heterogeneity of the Mn oxide (multiple reactive sorption sites). Furthermore, variation in $\mathrm{pH}$ and ionic strength had only a minor effect on the uptake behavior.

Synchrotron-based Extended X-ray Absorption Fine Structure Spectroscopy (EXAFS) was used to identify the local coordination environment of the predominant interfacial Sr species. The obtained molecular-level information is fundamental in determining the chemical reactions responsible for the observed macroscopic uptake behavior. The EXAFS results reveal that manganese occurs in the second coordination shell around $\mathrm{Sr}$ at a characteristic Sr-Mn distance of approximately $3.5 \AA$ over a wide range of solution conditions. This finding is consistent with the formation of inner-sphere $\mathrm{Sr}$ sorption complexes on the Mn-oxide surface.

At elevated $\mathrm{Sr}$ and/or carbonate concentration, $\mathrm{SrCO}_{3}$ precipitates were identified by EXAFS. Under the conditions at which precipitation was observed, the formation of $\mathrm{SrCO}_{3}$ is 
predicted using existing thermodynamic data. However, the identified $\mathrm{SrCO}_{3}$ precipitates revealed a higher degree of disorder compared to $\mathrm{SrCO}_{3}$ formed by homogeneous precipitation, which is interpreted as indicative of a surface precipitation process.

The present findings are of importance with respect to reliable risk assessment of nuclear (waste) facilities and technologies as well as for the development of sustainable environmental management and protection strategies. Furthermore, the knowledge gained of the chemical behavior of $\mathrm{Sr}$ at the manganese oxide - aqueous solution interface has implications for the development of future (off-site) ${ }^{90} \mathrm{Sr}$ waste treatment technologies as well as the design of adequate in-situ remediation schemes.

(7) A Study of the Iodine-Humic Materials Association using XANES and Principle Component Analysis (Jeffrey A. Warner and Gordon E. Brown, Jr.) (The results of this study are currently being prepared in manuscript form for submission to Environmental Science \& Technology.) - Radioactive isotopes of iodine $\left({ }^{129} \mathrm{I},{ }^{131} \mathrm{I}\right)$ and their interactions with environmental materials such as natural organic matter remain important for understanding the mobility of iodine at sites like Hanford in Washington State, Chernobyl in the Ukraine, Sellafield, England, and Cap La Hague in France. These latter two nuclear fuel reprocessing facilities are responsible for elevated radioactive I-129 levels detected in Sweden, according to a recent study by Buraglio et al. (2001). In the present study, we use iodine $\mathrm{K}$-edge and $\mathrm{L}_{3}$-edge XANES measurements in conjunction with principle component analysis (PCA) to identify the functional groups binding iodine in samples of iodine-containing leonardite soil humic acid (LHA), Pahokee peat (PP) and Aldrich humic acid (AHA).

A triiodide solution was prepared by adding $19.12 \mathrm{~g}$ of sodium iodide to about $40 \mathrm{~mL}$ of water. approximately $3 \mathrm{~g}$ of resublimed molecular iodine was added and the solution diluted to $100 \mathrm{~mL}$. The triiodide solution was standardized against $0.05 \mathrm{M}$ sodium thiosulfate which was itself standardized against $0.01 \mathrm{M}$ potassium iodate. The initial stoichiometric concentration of the triiodide solution prior to iodination of the humic and peat samples was $0.1185 \mathrm{M}$. Leonardite humic acid (LHA) standard (IS104H-5) and Pahokee peat (PP) was purchased from the International Humics Substances Society (IHSS) and an artifical humic acid was purchased from Aldrich. A solution of the LHA (12 g/L) was made in $0.1 \mathrm{M}$ sodium nitrate. The $\mathrm{pH}$ was adjusted to 8 using $10 \mathrm{~N} \mathrm{NaOH}$ allowing the LHA to dissolve and then re-adjusted to $\mathrm{pH} 6$ over several days. The LHA was iodinated by mixing $60 \mathrm{~mL}$ with $10.0 \mathrm{~mL}$ of I3- solution. The $\mathrm{pH}$ of the sorption solution after initial mixing was 5.5, which decreased to 4.7 after 24 hours of mixing on an orbital shaker. After 24 hours, the $\mathrm{pH}$ was adjusted to 3 and the mixture centrifuged. The iodine concentration of the supernatant was found to be $0.010 \mathrm{M}$ using standard techniques.

A suspension of PP $(8 \mathrm{~g} / \mathrm{L})$ was made in $0.1 \mathrm{M}$ sodium nitrate, the $\mathrm{pH}$ was adjusted from about 9.2 down to 5.5 using $\mathrm{HNO}_{3}$. The sorption suspension was made by combining $50 \mathrm{~mL}$ of the PP suspension with $10.0 \mathrm{~mL}$ of triiodide solution. The $\mathrm{pH}$ of the suspension after mixing was 5.0 which decreased to 4.75 after 24 hours of reaction. The suspension was treated as the LHA, the iodine concentration was $0.015 \mathrm{M}$ of the supernatant.

A solution of Aldrich sodium humate $(12 \mathrm{~g} / \mathrm{L})$ was adjusted to $\mathrm{pH} 5.5$ using $\mathrm{HNO}_{3}$. The humate was iodinated by mixing $60 \mathrm{~mL}$ of the Aldrich sodium humate solution with $10.0 \mathrm{~mL}$ of 
triiodide solution. The $\mathrm{pH}$ of the iodination mixture decreased over 24 hours from a $\mathrm{pH}$ of 5.0 to 4.3. The concentration of iodine decreased to $0.012 \mathrm{M}$ in the supernatant.

XANES measurements were performed on beamline 11-2 (K-edge) and beamline 4-3 ( $\mathrm{L}_{3}$-edge) at the Stanford Synchrotron Radiation Laboratory (SSRL). On beamline 11-2 the beam was appertured with a $1 \mathrm{~mm}$ vertical entrance slit and monochromatized using a Si (220) double crystal cooled with liquid nitrogen and typically detuned 50\% to minimize higher harmonics. Transmission mode was used to collect absorption spectra on the model compounds at the iodine $\mathrm{K}$ edge $(33169 \mathrm{eV})$. The IHSS leonardite humic acid, Aldrich humic acid and Pahokee peat sample spectra were collected in fluorescence mode because of their lower iodine concentrations. On beamline 11-2 a Canberra 30 element detector was used for fluorescence collection.

Spectra were collected at the iodine $\mathrm{L}_{3}$ edge $(4557 \mathrm{eV})$ on beamline 4-3 at SSRL using a Si (111) monochromator crystal calibrated at the scandium K-edge (4492 eV). A harmonic rejection mirror was used in the beam path with a cutoff energy of $7000 \mathrm{eV}$ with no subsequent detuning of the incident beam. In order to minimize air absorption of the incident x-ray beam, helium was used in the sample chamber and in a $30 \mathrm{~cm}$ ion chamber before the sample and the beam path through air was minimized as much as possible. Spectra were collected on model compounds and HM samples in fluorescence mode using a 13 element Ge fluorescence detector.

Figure 5 shows the I K-edge XANES spectra of the three I-NOM samples. Analyses of these spectra, as well as the EXAFS spectra, is underway.

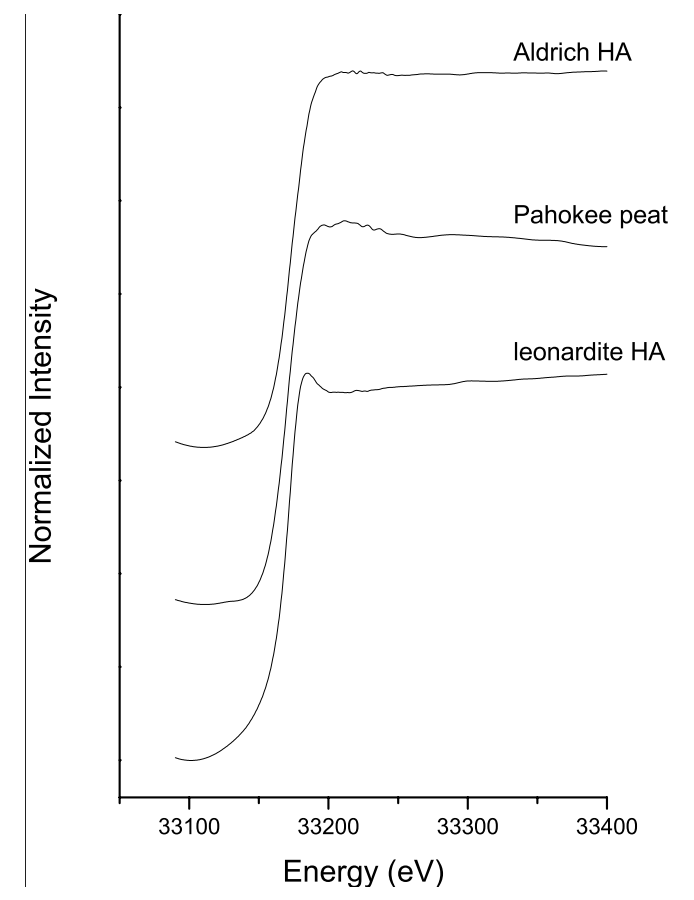

Figure 5. Normalized iodine K-edge XANES of several iodine-reacted IHSS leonardite humic acid, Pahokee peat and Aldrich sodium humate. 
(8) Hyperalkaline Aluminate Solutions: Effects of Temperature, Ionic Strength, and Contaminant Cations on Crystallization Kinetics and Mechanisms, Phase Stability, and Radionuclide Sequestration: A combined SAXS, WAXS, and Al-XANES Study (Samuel Shaw, Jeffrey A. Warner, Jeffrey G. Catalano, John Pople, and Gordon E. Brown, Jr.) (This study has recently been initiated and is underway.) - As part of a larger project aimed at gaining a fundamental understanding of the speciation and sequestration mechanisms of radionuclides such as ${ }^{60} \mathrm{Co}^{2+},{ }^{90} \mathrm{Sr}^{2+},{ }^{137} \mathrm{Cs}^{+}$, and ${ }^{234,238} \mathrm{U}^{6+}$ in vadose zone sediments beneath the Hanford, Washington High Level Waste Storage Tanks, we have initiated a project involving small angle X-ray scattering (SAXS), in situ X-ray diffraction (XRD), and XAFS spectroscopy to study the formation and changes with aging of Al-hydroxide polymers and solids in hyperalkaline aluminate solutions designed to simulate tank waste leachates. The key variables affecting the formation of Al-hydroxide polymers and crystalline precipitates are the total $\mathrm{Al}$ concentration, $\mathrm{OH} / \mathrm{Al}$ ratio and rate of $\mathrm{pH}$ neutralization, temperature, and time, and each will be varied independently in our crystallization experiments. Following our studies of Al-hydroxide polymer and solid formation in radionuclide-free solutions, we plan to add small quantities of $\mathrm{Co}, \mathrm{Sr}$, Cs, $\mathrm{U}$ and other key leachate species to the solutions and to determine their effects on polymer and solid formation and their incorporation into or sorption onto solid phases. Such processes provide a potentially important means of sequestering these contaminants and must be understood at a fundamental level in order to develop robust models for the fate and transport of tank leachate species at the Hanford Site.

Several periods of beam time have been used on SSRL BL 1-4 during which SAXS and WAXS data have been collected as a function of $\mathrm{Al}$ concentration, $\mathrm{OH} / \mathrm{Al}$ ratio, temperature, time, and rate of $\mathrm{pH}$ neutralization. We are currently analyzing these data.

\section{References Cited}

Ahearne, J.F. (1997) Radioactive Waste: the size of the problem. Physics Today, June, 24-29.

Benna, P. and Bruno, E. (2001) Single-crystal in situ high temperature structural investigation on strontium feldspar. Am. Mineral. 86, 690-696.

Boomer, K.D.; Baker, S.K.; Boldt, A.L.; Galbraith, J.D.; Garfield, J.S.; Golberg, C.E.; Higley, B.A.; Johnson, L.J.; Kupfer, M.J.; Marusich, R.M.; Parazin, R.J.; Praga, A.N.; Reddick, G.W.; Reddick, J.A.; Slaathaug, E.J.; Swanson, L.M.; Waldo, T.L. and Worcester, C.E.; (1994) Tank Waste Technical Options Report. WHC-EP-0616. Richland, WA: Westinghouse Hanford Co.

Buraglio, N., Aldahan, A., Possnert, G., and Vintersved, I (2001) I-129 from the nuclear reprocessing facilities traced in precipitation and runoff in northern Europe. Environ. Sci. Technol. 35(8), 1579.

Catalano, J.G., Warner, J.A. and Brown, G.E., Jr. (2001b) Spectroscopic investigation of Co and $\mathrm{U}$ speciation in model leachate-solid systems. Poster presentation at the $222^{\text {nd }}$ National Meeting of the American Chemical Society, August 2001, Chicago, IL.

Catalano, J.G., Warner, J.A., Chen, C-C., Yamakawa, I., Newville, M., Sutton, S.R., Ainsworth, C.C., Zachara, J.M., Traina, S.J. and Brown, G.E., Jr. (2001a) X-ray spectroscopic and fluorescence study of the speciation and distribution of chromium in Hanford S-SX Tank Farm core samples. Oral presentation at the $222^{\text {nd }}$ National Meeting of the American Chemical Society, August 2001, Chicago, IL. 
Chorover, J., Choi, S., Amistadi, M.K., Karthikeyan, K.G., Crosson, G., and Mueller, K.T. (2003) Linking cesium and strontium uptake to kaolinite weathering in simulated tank waste leachate. Environ. Sci. \& Technol. (in press).

Combes, J. M., Manceau, A., Calas, G., and Bottero, J. Y. (1989) Formation of ferric oxides from aqueous solutions: A polyhedral approach by x-ray absorption spectroscopy: I. Hydrolysis and formation of ferric gels. Geochim. Cosmochim. Acta 53(3), 583-594.

Combes, J. M., Manceau, A., and Calas, G. (1990) Formation of ferric oxides from aqueous solutions: A polyhedral approach by x-ray absorption spectroscopy: II. Hematite formation from ferric gels. Geochim. Cosmochim. Acta 54(4), 1083-1091.

Flanagan, B.D. (1994) Report \# WHC-SD-WM-TI-591, Pacific Northwest National Laboratory, Richland, WA.

Grolimund, D., Carrier, X., Warner, J.A., and Brown, G.E., Jr. (2000) Chemical behavior of strontium at the solid-liquid interface of amorphous manganese oxides: A molecular-level study using EXAFS. Oral presentation at the Tenth Annual V.M. Goldschmidt Conference, September 2000, Oxford, UK.

Frere, M.H. and Champion, D.F. (1967) Characterization of fixed strontium in sesquioxide gelkaolinite clay systems. Soil Sci. Soc. Amer. Proc. 31, 188-191.

Hayes, T.M. and Boyce, J.B. (1982) Extended X-ray absorption fine structure spectroscopy. Solid State Phys. 37, 173-351.

Hsu, P.H. (1967) Effect of salts on the formation of bayerite versus pseudo-boehmite. Soil Sci. 103(2), 101-110.

Hsu, P.H. (1989) Aluminum Hydroxides and Oxyhydroxides. In: Minerals in Soil Environments, $2^{\text {nd }}$ ed., eds. J.B. Dixon and S.B. Weed, Soil Science Society of America, Madison, WI.

Kinniburgh, D.G., Syers, J.K., and Jackson, M.L. (1975) Specific adsorption of trace amounts of calcium and strontium by hydrous oxides of iron and aluminum. Soil Sci. Soc. Amer. Proc. 39, 464-470.

Kinniburgh, D.G., Jackson, M.L., and Syers, J.K. (1976) Adsorption of alkaline earth, transition, and heavy metal cations by hydrous oxide gels of iron and aluminum. Soil Sci. Soc. Amer. J. 40, 796-799.

McGuinn, M.D. and Redfern, S.A.T. (1994) Ferroelastic phase transition along the join $\mathrm{CaAl}_{2} \mathrm{Si}_{2} \mathrm{O}_{8}-\mathrm{SrAl}_{2} \mathrm{Si}_{2} \mathrm{O}_{8}$. Amer. Mineral. 79, 24-30.

O’Day, P.A., Newville, M., Neuhoff, P.S., Sahai, N., and Carroll, S.A. (2000) X-ray absorption spectroscopy of strontium (II) coordination I. Static and thermal disorder in crystalline, hydrated, and precipitated solids and in aqueous solution. J. Coll. Interf. Sci. 222, 189197.

Ravel, B. (2001) Atoms: Crystallography for the X-ray absorption spectroscopist. J. Synchrotron Radiation 8, 314-316.

Reeder, R.J., Nugent, M., Tait, C.D., Morris, D.E., Heald, S.M., Beck K.M., Hess; W.P., and Lanzirotti A. (2001) Coprecipitation of uranium(VI) with calcite: XAFS, micro-XAS, and luminescence characterization. Geochim. Cosmochim. Acta 65(20), 3491-3503.

Serne, R. J. (2000) Workshop on High Level Waste Contaminated Sediments. EMSL, Pacific Northwest National Laboratory, Richland, WA. Oct. 24, 2000.

Serne, R. J. and Wood, M.I. (1990) Report \# PNNL-7279, DE90013546, Pacific Northwest National Laboratory, Richland, WA. 
Thompson, H.A., Parks, G.A., and Brown, G.E., Jr. (1999a) Ambient-temperature synthesis, evolution, and characterization of cobalt-aluminum hydrotalcite-like solids. Clays and Clay Minerals, 47, 425-438.

Thompson, H.A., Parks, G.A., and Brown, G.E., Jr. (1999b) Dynamic interactions of dissolution, surface adsorption, and precipitation in an aging cobalt(II)-clay-water system. Geochim. Cosmochim. Acta 63, 1767-1779.

van Straten H. A., Holtkamp, B.T.W., and de Bruyn, P.L. (1984a) Precipitation from supersaturated aluminate solutions I. Nucleation and growth of solid phases at room temperature. J. Coll. Interf. Sci. 98(2), 342-362.

van Straten H. A and de Bruyn., P.L. (1984b) Precipitation from supersaturated aluminate solutions II. Role of temperature. J. Coll. Interf. Sci. 102(1), 260-277.

van Straten H. A., Schoonen, M.A.A., and de Bruyn, P.L. (1984c) Precipitation from supersaturated aluminate solutions III. Influence of alkali ions with special reference to Li+. J. Coll. Interf. Sci. 103(2), 493-507.

Warner, J.A. and G.E. Brown, Jr (2001) Sorption-Desorption Behavior of Strontium in Aluminum Hydroxide Systems. Oral presentation at the $222^{\text {nd }}$ National Meeting of the American Chemical Society, August 2001, Chicago, IL

Zachara, J.M., Ainsworth, C.C., Brown, G.E., Jr., Catalano, J.G., McKinley, J.P., Oafoku, O., Smith, S.C., Szecsody, J.E., Traina, S.J., and Warner, J.A. (2003) Chromium speciation and mobility in a high level nuclear waste vadose zone plume. Geochim. Cosmochim. Acta 67 (in press). 